\title{
Juçara da Minha Cor: Reconhecendo e Valorizando o Território
}

\author{
Juçara of my Color: Recognizing and Valuing the Territory
}

\author{
SARAIVA, Gisele Reis Correa; Mestra; Universidade Federal do Maranhão - UFMA \\ gisarco41@gmail.com
}

SANTOS, Tayomara Santos dos; mestranda; Universidade Federal do Maranhão - UFMA

tayomara.ssantos@gmail.com

MATOS, Samara Lobo; graduada; Universidade Federal do Maranhão - UFMA

sah_lobo@hotmail.com

MORAES, Sâmela Patrícia Pereira; graduada; Universidade Federal do Maranhão - UFMA

samelapatricia.m@gmail.com

CORREA, Lucivaldo Silva Saraiva R.; graduando; Faculdade do Maranhão - FACAM

lucius_saraiva@hotmail.com

\section{Resumo}

Juçara, assim é conhecida no Maranhão a fruta que se popularizou pelo Brasil como açaí, fruto que, após a extração da polpa, as sementes são utilizadas para o artesanato. No entanto, no Maranhão embora tenha no seu território um grande contingente desse fruto, as sementes são descartadas após o despolpamento, fato que ocorre, principalmente, no bairro do Maracanã, onde se encontra o maior juçaral da capital, São Luís. No sentido de dar utilidade a esse resíduo, surge o Projeto "Artesanato no Maracanã" que, por meio de um trabalho conjunto com as artesãs locais, designers mediam o processo numa abordagem do design etnográfico (NORONHA, 2012) e a valorização do território (KRUKEN, 2009), promovendo oficinas direcionadas à utilização da semente de juçara em produções artesanais, resultando na organização de toda a cadeia produtiva que abrange o beneficiamento, criação/produção das peças e identidade visual do grupo, assim como a exposição e venda do produto.

Palavras Chave: Design; Artesanato; Território.

\begin{abstract}
Juçara, so it is known in Maranhão the fruit that became popular on Brazil as açaí, fruit that, after the extraction of the pulp, the seeds are used for the craft. However, in Maranhão although there is a large contingent of this fruit in its territory, the seeds are discarded after the extraction of the pulp, especially in the neighborhood of Maracanã, where the largest 'juçaral' in the capital, São Luis, is located. In order to give usefulness to this residue, the project "Handicraft in Maracanã" arises, which through a joint work with the local artisans, designers measure the process in an approach of ethnographic design (NORONHA, 2012) and the valorization of the territory (KRUKEN, 2009), promoting workshops aimed at the use of the seed of juçara in craft productions, resulting in the organization of the entire production chain that covers the processing, creation / production of the
\end{abstract}


items and visual identity of the group, as well as exhibition and sale of the product.

Keywords: Design; Crafts; Territory.

\section{Introdução}

Os produtos locais, de acordo com Kruken (2009, p.17), "são manifestações culturais fortemente relacionadas com o território e a comunidade que os gerou". A juçara, cultivada no bairro do Maracanã, é um produto que apresenta fortemente essas características, reconhecida em todo território maranhense e famosa por sua grande festa no mês de outubro, a Festa da Juçara. A juçareira, palmeira da qual se extrai a juçara, é uma espécie em que tudo se aproveita, porém, no Maracanã, bairro onde é cultivada, o que se destaca é o consumo da polpa. Com a extração da polpa, sobram as sementes que são descartadas.

Valois (2007) afirma que a semente de juçara, representa $83 \%$ do fruto, enquanto a parte comestível corresponde apenas $17 \%$. Portanto, a semente equivale mais da metade do que o fruto oferece e quanto maior seu desperdício, maior a perda de valores reais para a população que trabalha na extração e venda desse fruto, podendo dar uma utilidade a essa semente, que gere lucro, assim como a polpa. Especificamente, no Maracanã, milhares de sementes são jogadas fora todos os dias.

Para dá utilidade a essa semente, surge o Projeto "Artesanato no Maracanã", com o intuito de promover oficinas direcionadas à utilização da semente de juçara em produções artesanais, conduzindo as etapas do processo de beneficiamento da semente e desenvolvendo peças a partir da valorização do saber popular.

Este artigo relata o percurso desse Projeto, a partir do qual designers vão ao encontro da comunidade para mediar o processo, construindo um caminho adaptado à realidade local, em constante diálogo com as artesãs, sujeitos da pesquisa, baseando-se na metodologia do design etnográfico (Noronha, 2012), incorporando à pesquisa de design, os fundamentos da etnografia, conhecimento da antropologia e a etnografia aplicada ao design, proporcionando, no final, uma nova linha de produtos que irá beneficiar a sustentabilidade local.

\section{Juçara: "Joia Rara da Nação", Riqueza do Maracanã}

"Joia rara da nação", assim o grupo folclórico Companhia Barrica ${ }^{1}$ denomina a juçara (euterpe oleracea mart), fruta conhecida nos demais estados brasileiros como açaí, típica da região amazônica, cultivada nos estados do Pará, Amapá, Amazonas e Maranhão.

No estado do Maranhão, a juçara é um fruto muito apreciado, vários municípios possuem juçarais no seu território, inclusive a capital São Luís, onde seu maior contingente encontra-se no bairro rural do Maracanã. Por esse motivo, a mais de 40 anos foi criada a Festa da Juçara, a maior comemoração oficial de um fruto tipicamente amazonense dentro do Estado e que já faz parte das comemorações culturais do Maranhão.

A juçara movimenta durante o período de safra, a economia do bairro do Maracanã, principalmente durante a Festa da Juçara, realizada no mês de outubro. Várias famílias trabalham na colheita, processamento e venda da polpa e seus derivados (doces, pudins, bombons, sorvetes),

\footnotetext{
${ }^{1}$ Grupo de artistas formado em 1985, que revigora e evidencia a tradição da dança e brincadeira do Bumba-meu-boi, no Maranhão.
} 
contribuindo com a aumento da renda familiar (CORREA, 2010).

Da palmeira da juçara, além do fruto, também se utiliza, ainda que de forma incipiente, a folha seca, para artesanato, na confecção de arranjos florais; o cacho debulhado, como vassoura; o caule adulto e seco, para confeccionar bancos e como proteção para borda de riachos; e o caroço, que se restringe a produção de adubo e replantio, mas a maior parte é descartado, coletado pela companhia de limpeza urbana ou enterrado nos terrenos das propriedades das pessoas que trabalham com o processamento (CORREA, 2010).

\section{Valorizando o território, visualizando uma oportunidade}

É muito comum encontrar no artesanato do Maranhão, peças confeccionadas com sementes, principalmente em adornos, conhecidos como biojoias, porém, as sementes utilizadas na confecção das peças, são provenientes de outros estados, em especial dos estados da região norte, embora o Maranhão possua na sua vegetação, muitas espécies produtoras de sementes, usadas para esse tipo de trabalho, com destaque à semente de juçara. Como em São Luís, no bairro do Maracanã se encontra o maior juçaral da llha e, por isso, tem a Festa da Juçara todos os anos, o que fez surgir a inquietação sobre o que era feito com as sementes após a extração da polpa.

Kruken (2009, p.18) afirma que "Para dinamizar os recursos do território e valorizar seu patrimônio cultural, é fundamental reconhecer e tornar reconhecíveis valores e qualidades locais". Nesse sentido, foi realizada entre os anos de 2008 e 2010, no bairro do Maracanã, uma pesquisa em que foi constatado que a maior parte da semente de juçara era descartada, não tendo nem uma utilidade após o despolpamento. De posse desses dados, foram elaboradas recomendações para o uso da semente de juçara na produção de peças artesanais, pautado em teorias de design, artesanato, cultura, gestão de design e sustentabilidade (CORREA, 2010).

Constatado a potencialidade da matéria prima na localidade, realizou-se durante os anos 2016 e 2017, o Projeto de Extensão "Artesanato no Maracanã", com professores e alunos do Núcleo de Pesquisa em Inovação Design e Antropologia - NIDA, do curso de Design, da Universidade Federal do Maranhão.

Nesse contexto, utilizou-se o design etnográfico, que propõe vincular à pesquisa de design, os fundamentos da etnografia e conhecimento da antropologia (NORONHA, 2012). O design incorporado à área da etnografia, possibilita ao designer se colocar não como um agente centralizador, detentor do saber, mas como mediador, colocando-se no meio do sujeito de pesquisa, em igual proporção e peso de decisão.

Dessa forma, o designer, por estar na posição de mediador, pode ser considerado como integrante do grupo de autores sociais e participar diretamente das estratégias em busca do desenvolvimento sustentável, "ligando o tecnicamente possível com o ecologicamente necessário, fazendo nascer novas propostas que sejam social e culturalmente apreciáveis" (MANZINI; VEZZOLI, 2008, p.20).

Numa parceria com diversas mulheres da comunidade, construímos coletivamente um percurso por meio de seminários, palestras, rodas de conversa, oficinas, experimentos, que se concretizou na formação de um grupo e desenvolvimento de produtos a partir da valorização do saber popular, gerando, dessa forma, uma nova oportunidade de renda para a população da comunidade. 
Esse percurso, permitiu a elaboração da cadeia produtiva ${ }^{2}$ do artesanato com a semente de juçara, enfatizando desde o momento da coleta até a exposição e a venda do produto artesanal. As etapas foram nomeadas de beneficiamento, criação/produção e exposição e venda, as quais serão apresentadas nos itens a seguir.

\section{Lapidando a Joia Rara}

As sementes de juçara antes de se tornarem peças artesanais, precisam ser submetidas a um tratamento/processo para adquirir resistência, cor e aparência ideais ao fim proposto. A etapa de beneficiamento, responsável por todo esse processo, se apresenta em onze sub etapas: coleta, lavagem, secagem, lixamento, seleção, furação, imunização, tingimento, polimento, banho com óleos naturais e armazenagem.

\subsection{Coleta}

A coleta da semente é feita nos pontos de venda de polpa da juçara, dentro do próprio bairro do Maracanã, tendo sempre o cuidado de coletar sementes de frutos que foram processados no dia ou até dois dias anteriores, para que não fiquem expostas por muito tempo, o que pode ocasionar a proliferação de fungos e a exposição ao sol, podendo vir a comprometer a estrutura da semente, tornando-a frágil e quebradiça (MATOS et al, 2007). As sementes são coletadas em baldes ou sacos plásticos, com uso de Equipamentos de Proteção Individual - EPI's, luvas e sapatos fechados para evitar o contato direto, pois algumas vezes as sementes são descartadas com outros produtos.

Figura 1 - Coleta de sementes

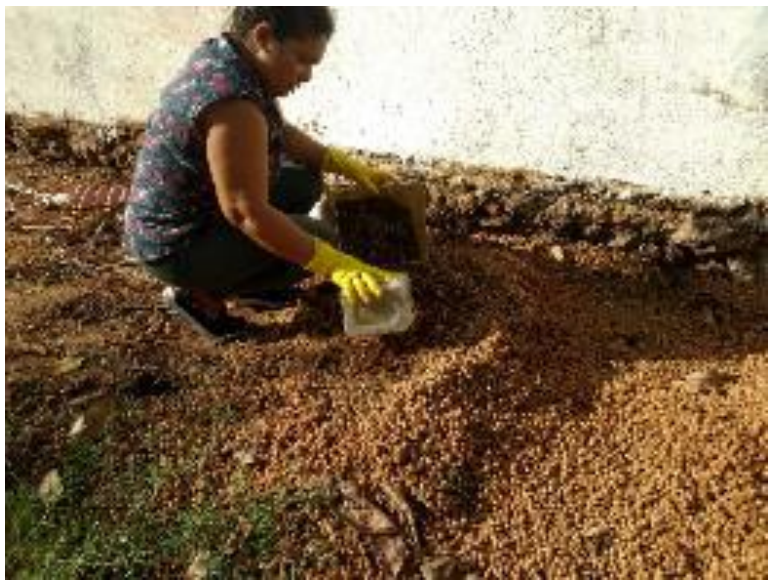

Fonte: os autores (2017)

\subsection{Lavagem}

As sementes após coletadas são lavadas, para retirar as sobras de resíduos provenientes do despolpamento, em recipientes com furos, facilitando o escoamento da água e resíduos.

\footnotetext{
2 "Conjunto de procedimentos, etapas, agentes, processos e produtos, desde a sua pré-produção até o consumo final" (NORONHA, 2011, p.15)
} 
Figura 2 - Lavagem da semente

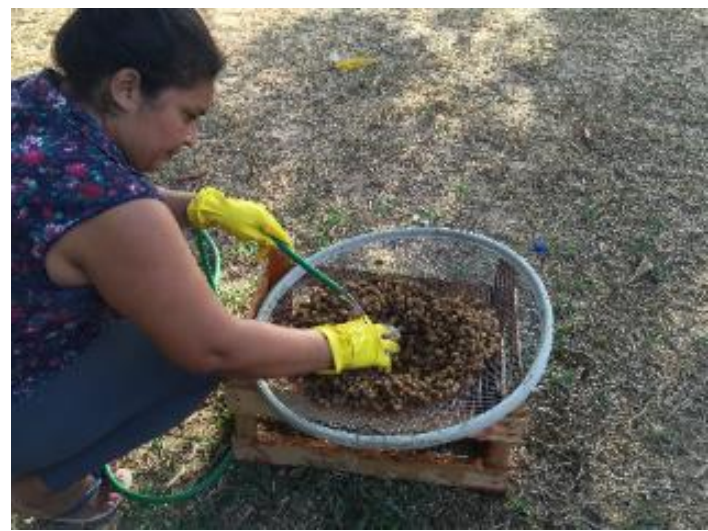

Fonte: os autores (2017)

\subsection{Secagem}

O processo de secagem consiste na retirada parcial de água da semente por meio da transferência simultânea de calor do ar para a semente e de água, por meio de fluxo de vapor, da semente para o ar (PESK et al, 2012).

Para a secagem da semente, usamos o método de secagem natural que, de acordo com Garcia (201-), utiliza as energias solar e eólica para remover a umidade das sementes, utilizando recursos como eiras ou lonas. Por ser um método de secagem demorado, é recomendado o uso de telas de plástico ou arame entrelaçado, formando uma peneira. As sementes são esparramadas em forma ondulada sobre a peneira, a qual é, posteriormente, erguida a uma altura de 0,5 a 1,0m do solo, possibilitando que o ar passe por cima e por baixo das sementes, abreviando consideravelmente o tempo de secagem (PESK et al, 2012).

Cuidados especiais devem ser tomados para que as sementes não sofram aquecimento excessivo e que a secagem ocorra do modo mais uniforme possível:

- Secar à sombra;

- As camadas de sementes não devem ultrapassar $5 \mathrm{~cm}$ de altura.

- Revolver as sementes frequentemente, para que todas sejam expostas ao ar. No caso de sementes que são lavadas, essa movimentação é essencial, caso contrário poderá haver um gradiente muito grande de umidade na semente que pode ocasionar rupturas internas;

- Encobrir as sementes no período noturno.

Este método, em geral, é pouco suscetível a riscos de danificação mecânica e térmica, porém mais indicado e adequado quando se utiliza quantidade de sementes reduzidas (Garcia, 201-).

De posse dessas informações, as sementes de juçara lavadas são colocadas para secar à sombra, em telas de plástico sobre uma armação de metal, ou em peneiras de arame, para que o ar circule de forma uniforme. Durante várias vezes ao dia as sementes são remexidas para que sequem proporcionalmente. No período da noite são cobertas, para evitar absorção de unidade. Após dois a três dias, dependendo das condições climáticas, as sementes estão prontas para serem lixadas. 
Figura 3 - Secagem natural

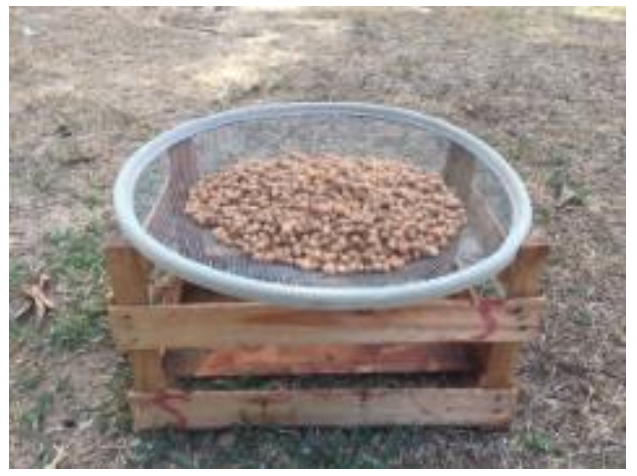

Fonte: os autores (2017)

\subsection{Lixamento}

A etapa de lixamento é realizada com o auxílio de uma máquina produzida pela equipe executora, com materiais de baixo custo e sucatas. Esta etapa iniciou com vários testes, utilizando diversos tipos de lixas, até a escolha de lixas adequadas, cujas lixas para madeira foram consideradas as mais eficientes para este serviço, nos números 60,80 e 100, cada uma utilizada no tempo de 3 a 4 minutos. A Lixa 60, por apresentar o maior grão, é responsável pela retirada da parte mais grossa, a casca que envolve a semente, fase que denominamos 'despelamento'. Após o 'despelamento', percebemos que a semente é rajada, revestida por uma camada marrom. A lixa 80 retira as sobras dos resíduos deixados após a lixa 60 e passa a lixar a semente, deixando o rajado bem evidente, e a cor marrom menos acentuada. Com a lixa 100, o rajado se sobressai e toda a camada marrom é retirada, dando lugar a coloração natural que varia do branco a um tom bege. Consideramos este ponto ideal para a execução da etapa seguinte.

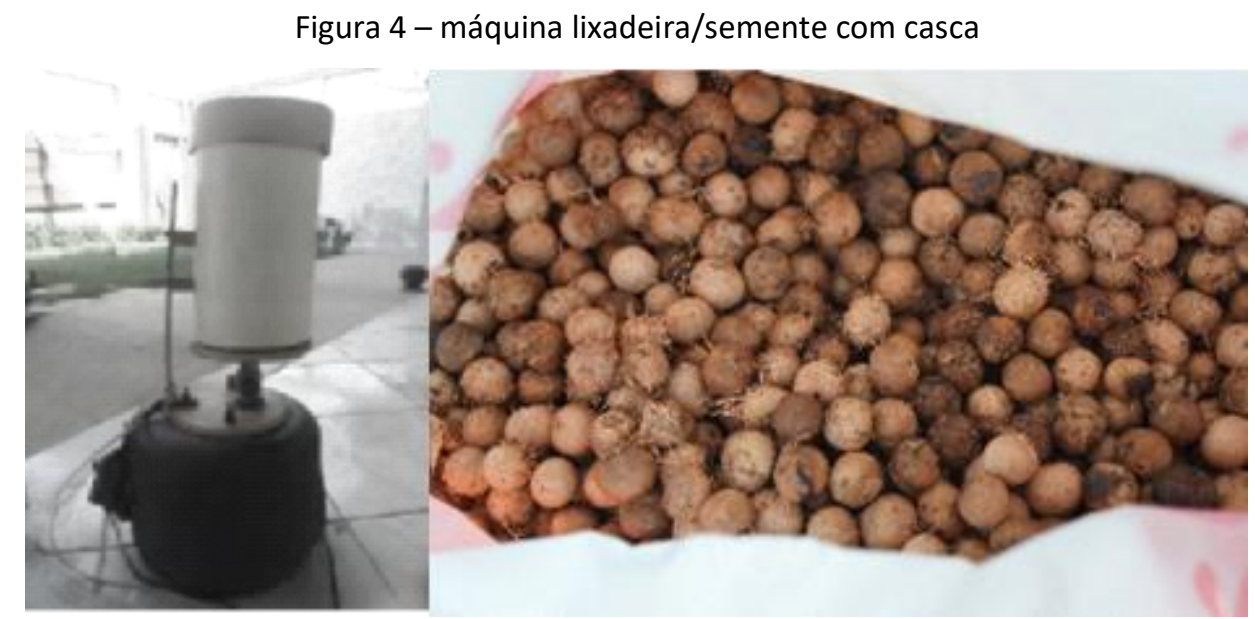

Fonte: os autores (2017) 
Figura 5 - Sementes lixadas com lixa 60, 80, 100

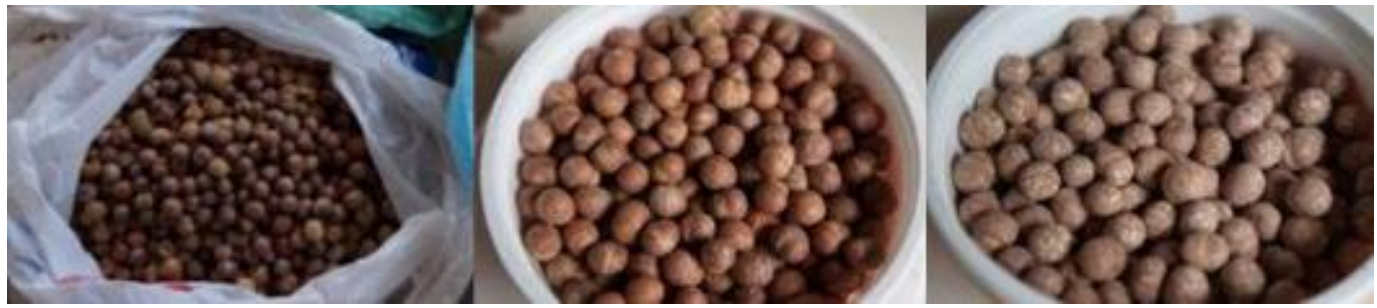

Fonte: os autores (2017)

\subsection{Seleção}

Esta etapa é realizada manualmente para retirada de sementes sem condição de uso, ou seja, sementes quebradas no processo de lixamento, ou então estragadas por ação de microrganismos.

Figura 6 - Seleção de sementes/sementes descartadas

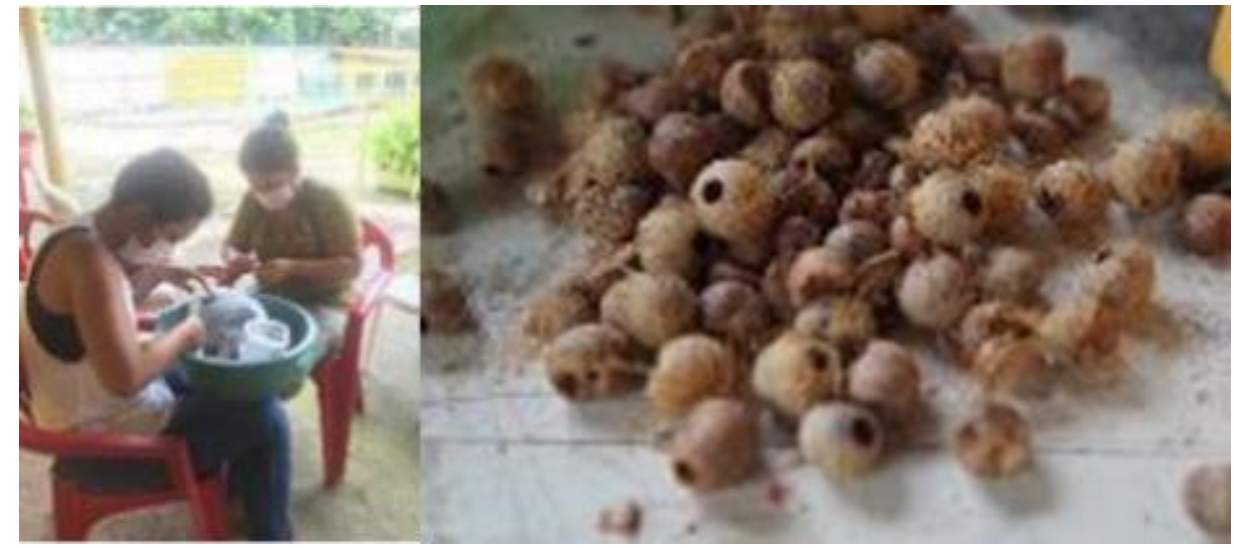

Fonte: os autores (2017)

\subsection{Furação}

A furação é feita, por unidade de semente, com uso de furadeira de bancada e brocas escolhidas de acordo com o tamanho do furo desejado, sem comprometer a qualidade aparente da semente.

A semente de juçara tem formato quase esférico, com medidas que variam entre 6 a $10 \mathrm{~mm}$ de diâmetro, portanto, há necessidade de um alicate para auxiliar na hora do furo. $O$ furo é executado no poro germinativo, para evitar a germinação da semente. O formato da semente e poro germinativo marcante, facilitam a execução do furo. Mas, ainda busca-se uma forma de facilitar a furação, para que as artesãs possam furar várias sementes de uma vez. 
Figura 7 - Furação/sementes furadas no poro germinativo

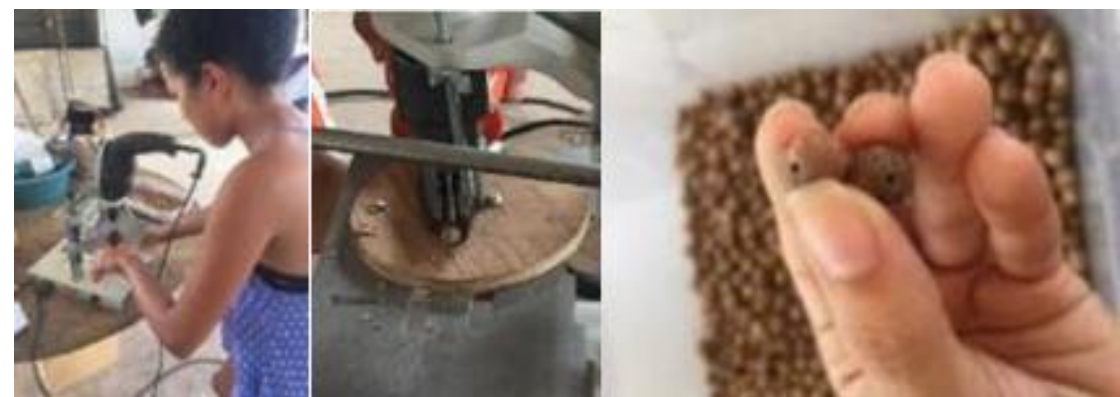

Fonte: os autores (2017)

\subsection{Imunização}

Sementes são vulneráveis ao ataque de insetos, fungos e microorganismos, por esse motivo, quando não são tratadas devidamente comprometem a qualidade dos produtos artesanais a que são destinados.

Quando chegamos ao Maracanã, as artesãs realizavam o artesanato de arranjos florais utilizando a palha da juçara na confecção de flores e troncos de árvores, os 'mondrongos', como base dos arranjos. Para imunizar esses troncos, elas utilizam inseticidas.

Ao começarmos a realizar o processo de beneficiamento e precisamente na etapa de imunização, foi sugerido por elas o uso desse mesmo material para imunização das sementes.

Numa roda de conversa, esclarecemos que essas substâncias são tóxicas e os malefícios que podem trazer a saúde. Mostramos que podemos imunizar as sementes, utilizando produtos menos danosos. Apresentamos então a proposta da Doutora Denise Vilela, agrônoma e professora da Universidade de Brasília, que elaborou o manual de instruções para tratamentos de artesanato com procedimentos dos tratamentos de insumos e sementes (MATOS et al, 2007).

O tratamento consiste em duas técnicas, a primeira com uso de álcool e a segunda com água sanitária. As sementes precisam estar furadas para que as soluções empregadas entrem nos furos para tratá-los também.

Solução com álcool é feita com 1 litro de álcool e 1 litro de água, colocados em um recipiente com $1 \mathrm{~kg}$ de semente, que depois de remexido com as mãos por alguns instantes é deixado de molho por 10 minutos, depois retirado e, logo em seguida, colocado em solução de $100 \mathrm{ml}$ de água sanitária para 2 litros de água, procedendo da mesma forma da solução com álcool. Após o processo, as sementes são colocadas em lugar a sombra para secar, por dois ou mais dias, dependendo das condições climáticas.

Figura 8 - Imunização das sementes

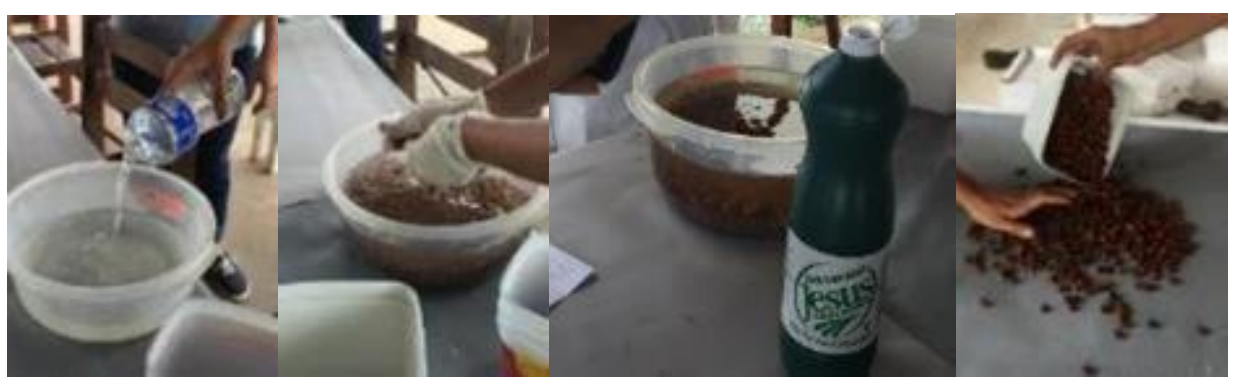

Fonte: os autores (2017) 


\subsection{Tingimento Natural}

A semente de juçara é rajada e sua coloração natural varia do branco a um tom bege, podendo ser usada dessa forma para a confecção das peças artesanais, porém no intuito de ter uma variedade de tons para dar mais diversidade na elaboração das peças, optamos também por tingilas.

O tipo de tingimento escolhido foi o tingimento natural, utilizando pigmentos encontrados na própria vegetação da comunidade, tais como: a própria juçara, o açafrão (Curcuma longa), o urucum (Bixa Orellana L.), murici do mato (Byrsonima crassifólia) e aroeira (Myracrodruon urundeuva).

A técnica utilizada foi baseada nos estudos de Ferreira e Gomes (2005), denominada de tingimento à quente, feita por meio do cozimento sem uso de mordente ou aglutinante ${ }^{3}$. Essa técnica foi escolhida como procedimento mais adequado devido à facilidade do corante impregnar na superfície da semente. Com o tingimento a frio, o corante fica superficial e solta com o manuseio

De um modo geral, o processo é realizado misturando as sementes com o colorante em estado líquido e levado ao fogo, quando atingi o ponto de fervura cronometra-se 10 minutos, tempo suficiente para o corante impregnar na semente. Após esse tempo a mistura é retirada do fogo, posta para esfriar naturalmente, em seguida as sementes são lavadas, para retirar o excesso do composto e colocadas para secar a sombra por dois ou mais dias (SARAIVA; SANTOS, 2017).

Figura 9 - Processo de tingimento natural

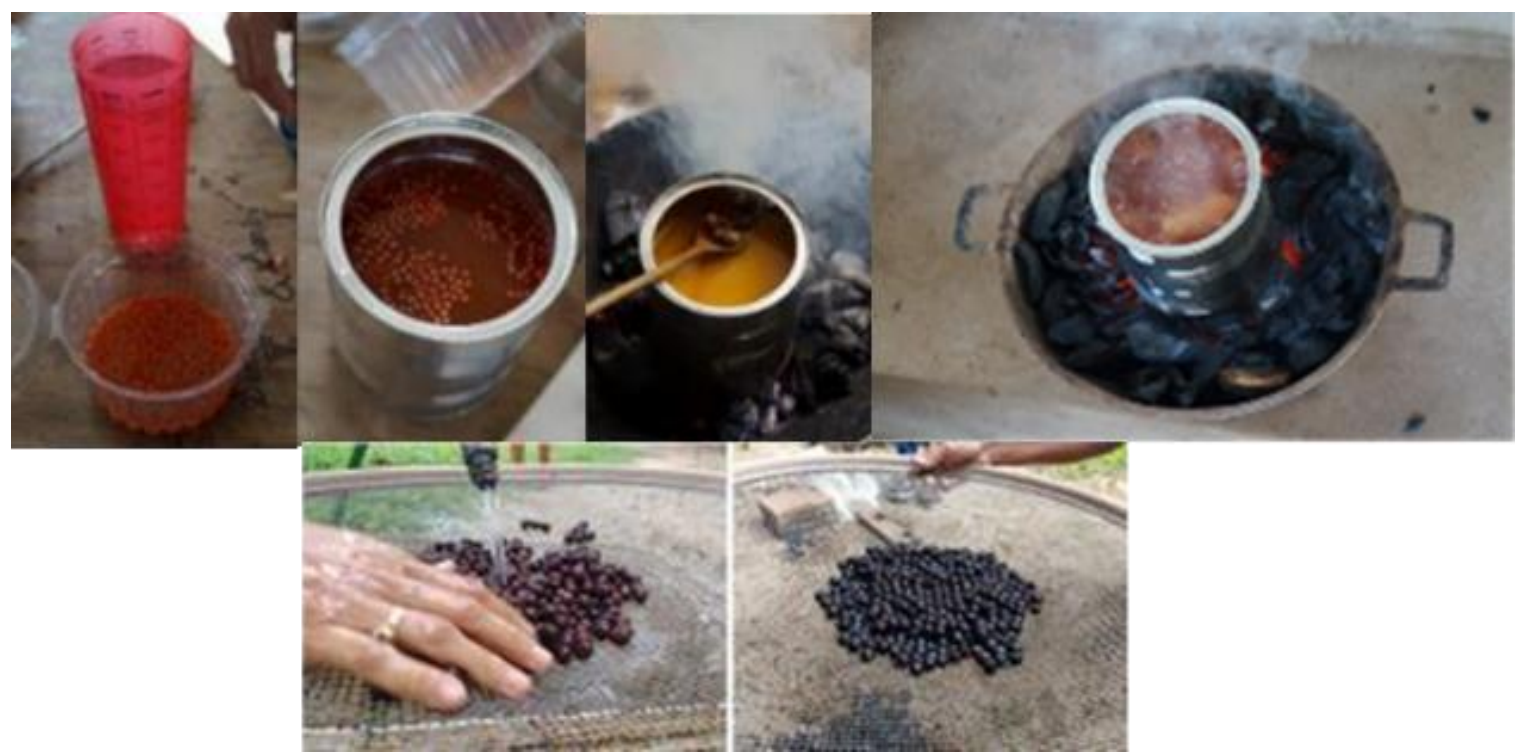

Fonte: os autores (2017)

\footnotetext{
${ }^{3}$ Material que ajuda a fixação do corante na superfície do substrato a ser tingido. (FERREIRA; GOMES, 2005)
} 
Figura 10 - Resultado do tingimento

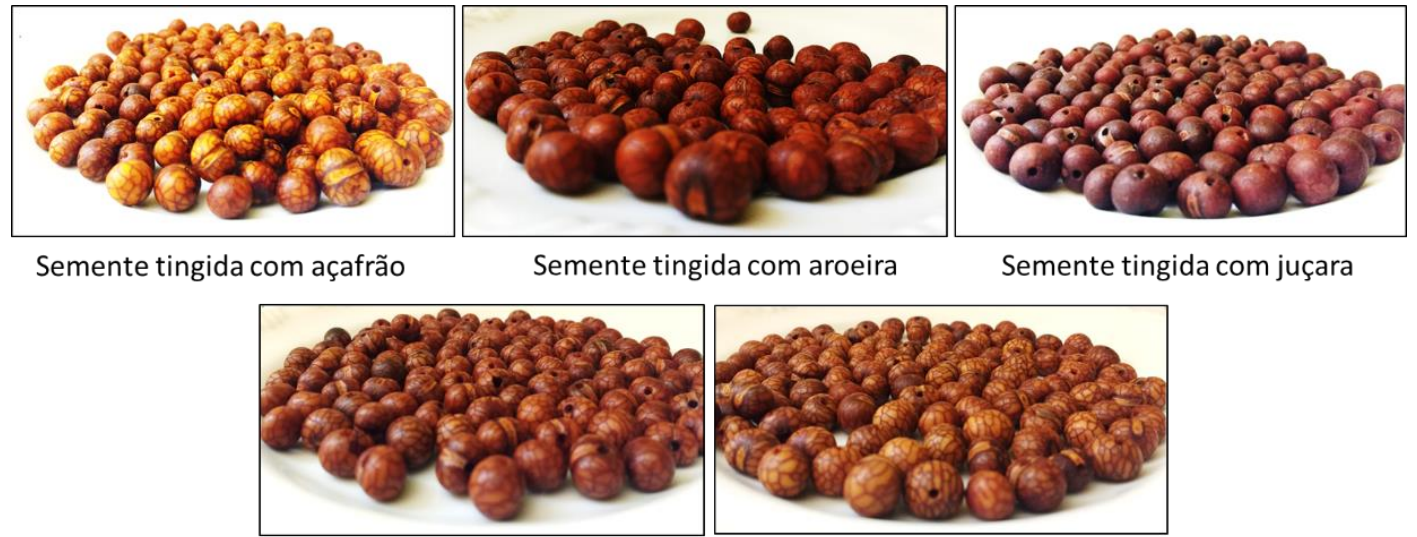

Semente tingida com murici-do-mato Semente tingida com urucum

Fonte: os autores (2017)

\subsection{Polimento}

Para o polimento das sementes, é utilizada a mesma máquina da etapa de lixamento, mas utilizando as lixas 600 e 1200, com duração de dois minutos para cada lixa. Esta etapa ocorre depois da imunização apenas para as sementes que permanecerem com a cor natural, caso as sementes precisem ser tingidas, o polimento só ocorre após o tingimento.

Figura 11 - Sementes após o polimento

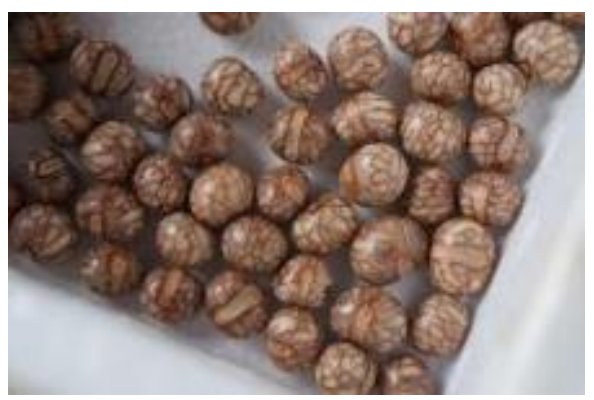

Fonte: os autores (2017)

\subsection{Banho com óleo natural}

A semente, além da imunização com álcool e água sanitária, depois do polimento, recebe uma proteção com óleo natural, contra o desenvolvimento de fungos e outros microrganismos (MATOS et al, 2007). Para as sementes de juçara usamos o óleo de andiroba, rico em valor medicinal, facilmente encontrado no mercado local e por um preço acessível.

As sementes recebem banho em óleo natural na proporção de 1 colher (sopa) de óleo para 1 quilo de semente, mexendo por 10 minutos para que o óleo possa aderir na semente, assim como entrar nos furos. Depois, as sementes são colocadas em saco plástico simples, transparente e guardadas em saco plástico preto, amarrado com o nó para vedar a entrada de ar, deixando um espaço entre as sementes e o nó. Dessa forma, são guardadas por dois dias para só depois serem 
utilizadas na confeç̧ão das peças artesanais.

Figura 12 - Banho com óleo natural

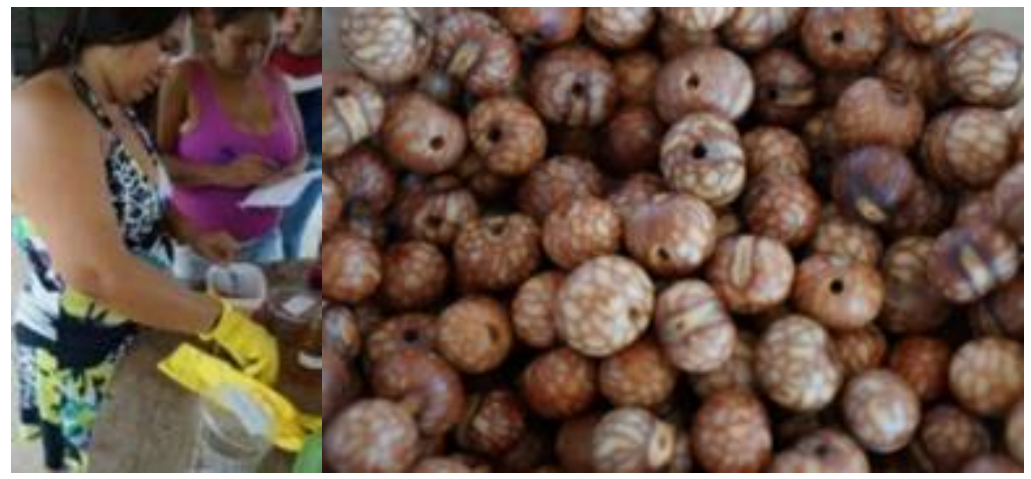

Fonte: os autores (2017)

\subsection{Armazenagem}

Após o banho de óleo natural, as sementes estão prontas para serem utilizadas e devem ser guardadas de modo adequado para que sejam protegidas e estejam sempre em condições de uso. Separamos as sementes por cores e condicionamos em recipientes plásticos com tampa e sachê de sílica gel, para evitar umidade (MATOS et al, 2007; LEÃO et al, 2009).

Figura 13 - Sementes armazenadas, prontas para uso

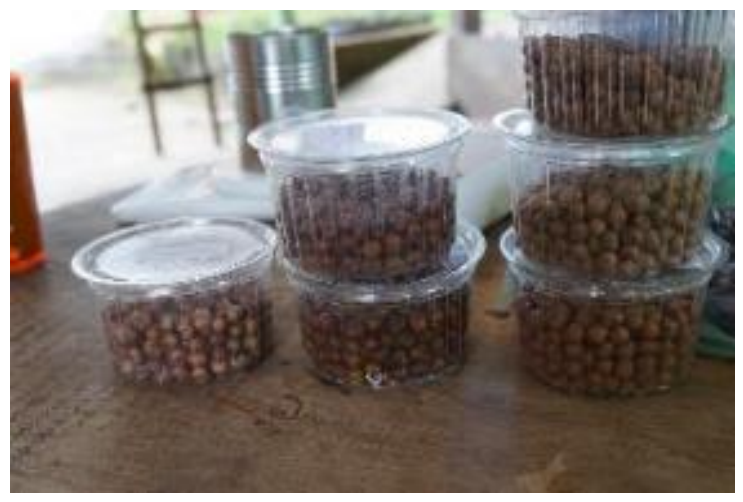

Fonte: os autores (2017)

\section{Criação/produção: valores identitários da comunidade}

Estimular o reconhecimento das qualidades e dos valores relacionados com o produto local - qualidades referentes ao território, aos recursos, ao conhecimento incorporado na sua produção e à sua importância para a comunidade produtora - é uma forma de contribuir para tornar visível à sociedade a história por trás do produto. (KRUKEN, 2009, p.22)

Finalizado o processo de beneficiamento, as sementes estão prontas para tornarem-se produtos, porém esse era o primeiro contato das artesãs com esse tipo de material. Escolhemos como segmento de mercado, a moda com foco nos adornos, especificamente a biojoia, tendo em vista ser o produto mais encontrado no mercado, confeccionados com sementes e com forte apelo de diferenciação. A partir de então foi discutido e desenvolvido todo um processo para que as artesãs tivessem autonomia na preparação de uma coleção. 
Foram mediadas oficinas de moda para o desenvolvimento da coleção, oficinas de técnicas manuais com fios para elaboração dos cordões como base para as sementes e, utilização de textos, músicas, imagens, memórias sobre o imaginário e repertório das artesãs. De todo esse processo surgiu a coleção "Bumba-meu-boi do Maracanã", em homenagem ao folguedo de maior representatividade da comunidade e dentro do estado do Maranhão, conhecido como "batalhão pesado", por arrastar uma grande multidão nas suas apresentações, principalmente durante as festas juninas. Para criação da coleção foi utilizado como inspiração todo o enredo do bumba meu boi do Maracanã, tais como personagens, indumentária (vestimenta), instrumentos e as suas cores específicas, verde, vermelho, azul e amarelo (LOBO; SARAIVA, 2017).

Figura 14 - Bumba Meu Boi do Maracanã

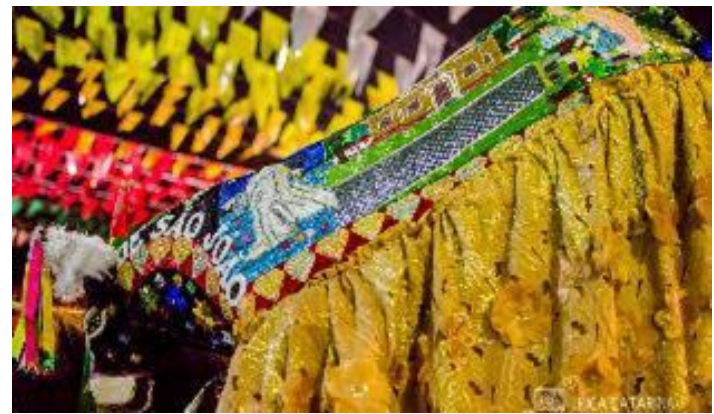

Fonte: Blog Erica Catarina (2016)

Figura 15 - Coleção Bumba Meu Boi do Maracanã

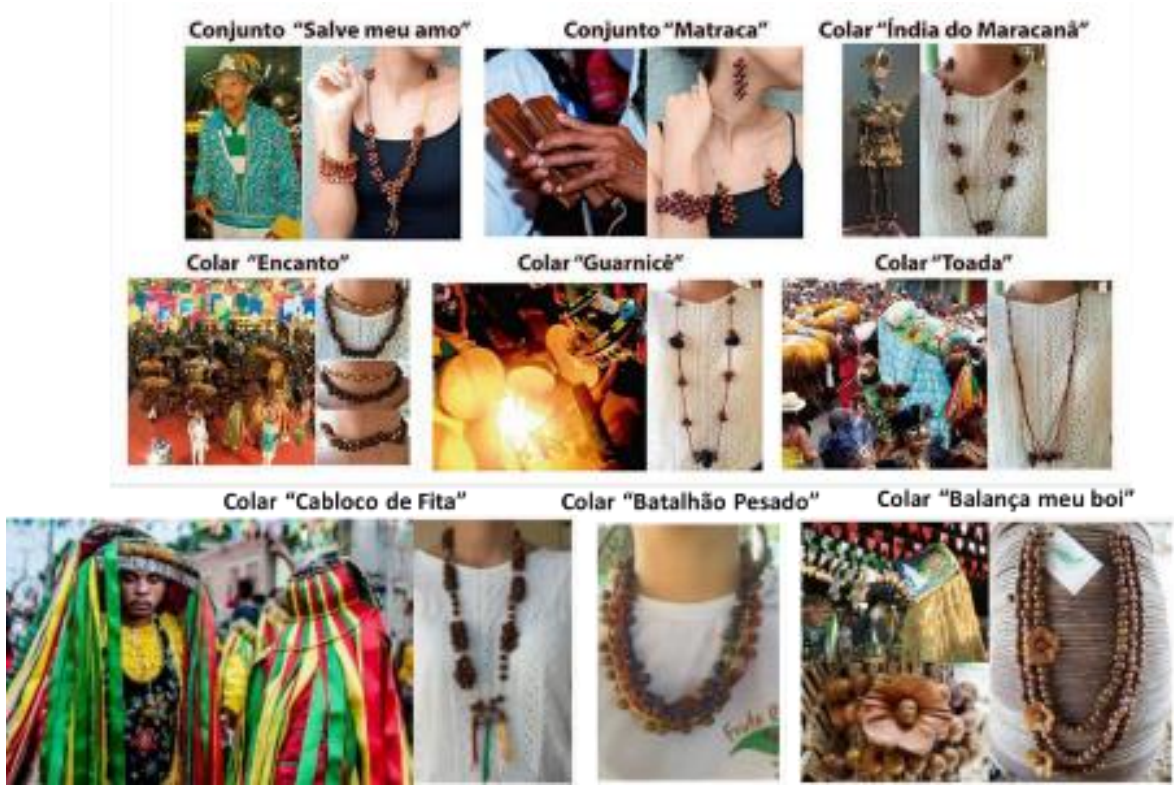

Fonte: os autores (2017)

Após todo o processo de criação da coleção, as artesãs entenderam a importância dos valores identitários da comunidade para valorização e reconhecimento do seu produto, o que influenciou também na definição do nome do grupo e a criação da identidade visual. 
O nome do grupo surgiu a partir da escuta de várias músicas do repertório maranhense, e por um processo de votação o nome escolhido foi "Fruta Rara", trecho da música "Ilha Bela", do cantor maranhense Carlinhos Veloz, em que o mesmo cita: "Quero juçara, que é fruta rara, lambuza a cara e lembra você". (SARAIVA; MORAES, 2018)

Com o nome definido, a identidade visual, como parte do processo de criação, também teve a participação conjunta das artesãs. Dessa co-participação, surgiram desenhos utilizados nas aplicações dos produtos e uma frase, dita por uma das artesãs, que serviu de referência para criação da marca: "A juçara se transforma em joia rara nas mãos das mulheres do Maracanã".

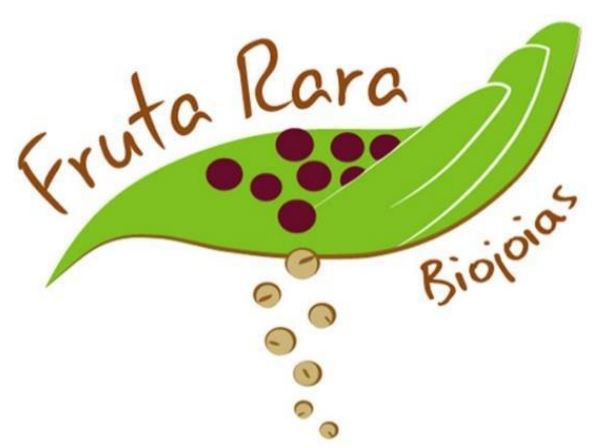

Fonte: os autores (2017)

Figura 17 - Aplicações

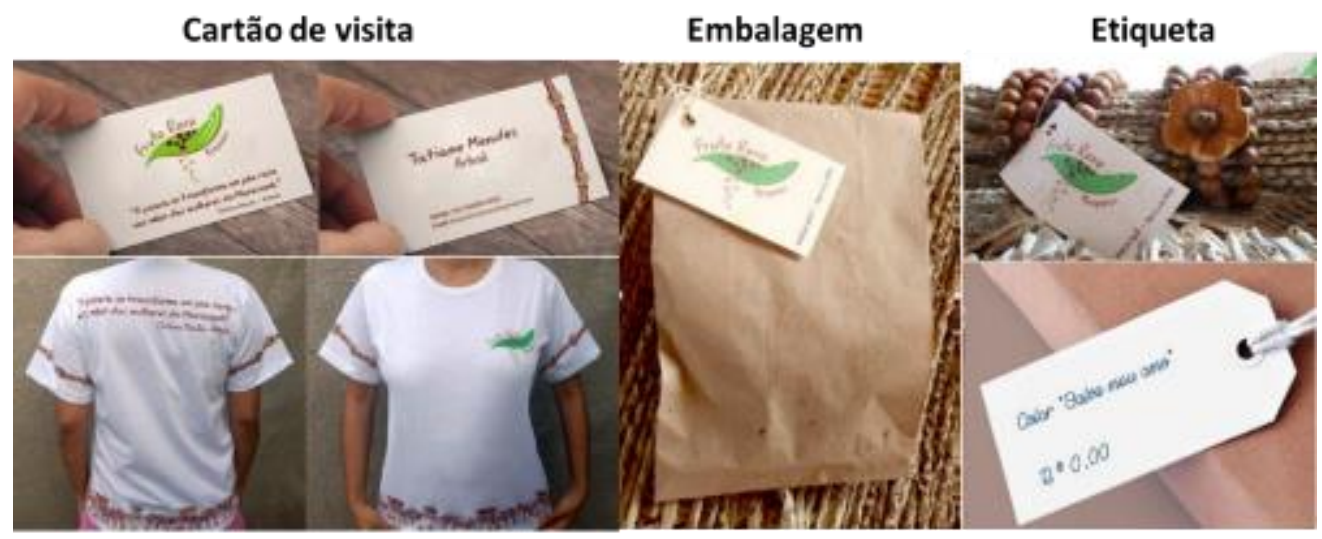

Camisa

Fonte: os autores (2017)

\section{6 "Tempo certo de se ouvir, Maracanã"4}

Um dos propósitos do projeto era que, ao final de todo processo, as artesãs pudessem expor e vender as peças criadas. Para culminância, escolheu-se o período da Festa da Juçara. Nesse

\footnotetext{
${ }^{4}$ Trecho da música "Voa Maracanã”, do grupo folclórico Companhia Barrica.
} 
momento as artesãs puderam apresentar o artesanato com o novo tipo de material, já conhecido por todos, mas que, até então, não tinha nem uma utilidade no Maracanã. A exposição teve grande visibilidade, tanto pelo uso do material, como pela escolha do nome da coleção, onde todos puderam identificar elementos do bumba meu boi do Maracanã, nas peças. Após a Festa da Juçara algumas parcerias foram formadas, para exposição e venda das peças, como pousadas localizadas na Avenida Litorânea, situadas na praia do Calhau, ponto turístico de São Luís e, também, em feiras de artesanato local, pelas próprias artesãs.

Figura 18 - Exposição e venda na Festa da Juçara

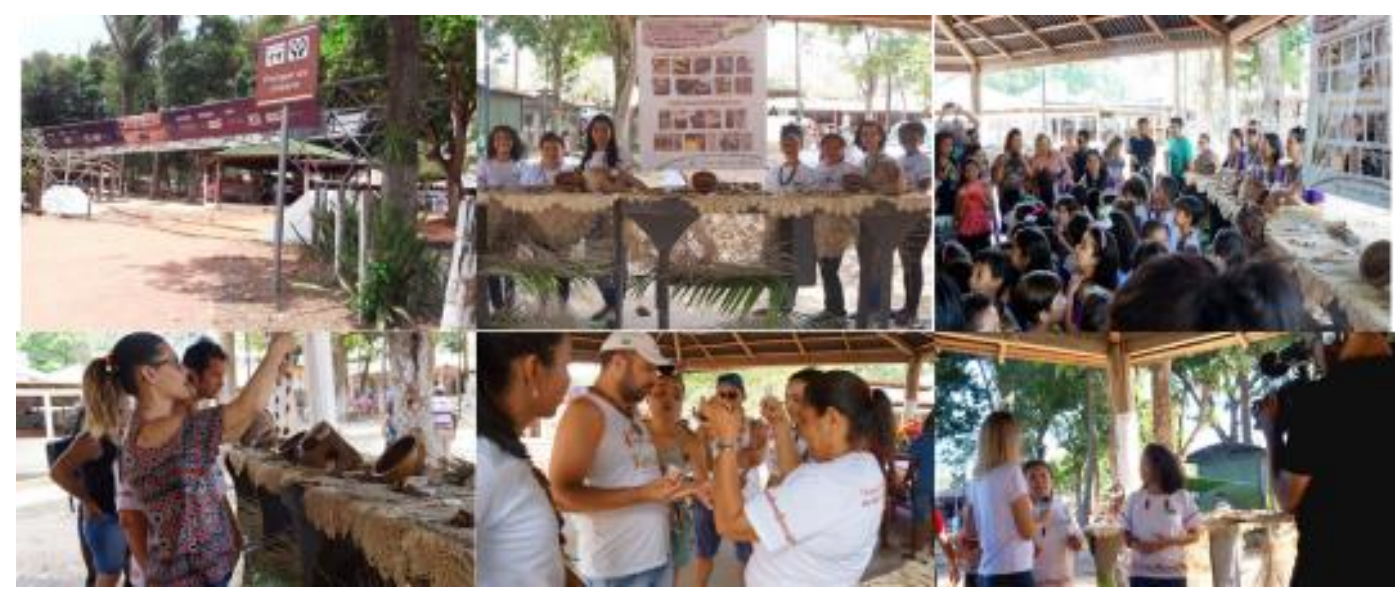

Fonte: as autoras (2017)

\section{Conclusão}

A juçara sempre teve para a população maranhense um significado muito especial, por dois motivos: o primeiro se refere ao nome pelo qual é chamada, ou seja, "juçara" é exclusiva do linguajar maranhense, sendo, portanto sempre juçara, jamais açaí; e, segundo, por tudo que a envolve, como a beleza da sua palmeira e dos seus cachos, o sabor da sua polpa, a maneira de degustá-la, seja com farinha, com camarão ou com açúcar e a sua cor, impregnada no dia a dia do maranhense.

Diante dessa importância, a semente da juçara não pode e nem deve ser vista como algo que está à parte do fruto. A oportunidade de trabalhar com a semente levou as artesãs e a equipe executora do projeto a valorizar o fruto como um todo, mostrando que a importância da juçara não finda com a extração da polpa, mas que recomeça, com um outro ciclo, o da semente, que no caso dessa pesquisa, suscitou na confecção de produtos artesanais, em específico, as biojoias.

Durante o percurso do projeto, pode-se construir um conhecimento coletivo, em que as artesãs e designers, num processo de co-criação, puderam dar uma solução para uso do objeto estudado, identificando as reais necessidades da comunidade, alinhando a fatores de sustentabilidade. Nesse aspecto, percebe-se a importância do design em todas as fases do processo produtivo, executando uma tarefa complexa de mediar produção e consumo, tradição e inovação, qualidades locais e relações globais, assim como afirma Kruken (2009).

Como todo o processo foi realizado juntamente com as artesãs, acredita-se que estas têm autonomia para prosseguir e, até mesmo, encontrar outras possibilidades de uso para a semente, 
além de agregar a outros materiais encontrados no entorno.

A elaboração da cadeia produtiva para o artesanato com semente de juçara, mostrou às artesãs que atividade artesanal, necessita de direcionamento com etapas elaboradas e testadas, cujos produtos desenvolvidos, precisam carregar os valores e qualidades do contexto local para serem reconhecidos e, dessa forma, gerar renda e fortalecer a atividade.

\section{Referências}

CORREA, Gisele Reis. Design e artesanato: um estudo de caso sobre a semente de juçara em São Luís do Maranhão. 2010. 144f. Dissertação (Mestrado) - Programa de Pós-graduação em Design, Universidade Federal de Pernambuco, Recife, 2010.

FERREIRA, Eber Lopes; GOMES, Selma (org). Tingimento Vegetal: teoria e prática sobre tingimento com corantes naturais. São Paulo: FNMA, 2005.

GARCIA, Danton Camacho. Secagem de Sementes. Santa Maria: UFSM, [201-].

KRUCKEN, Lia. Design e território: valorização de identidades e produtos locais. São Paulo: Studio Nobel, 2009.

LEÃO, N. V. M.; FREITAS, A. D. D. de; NASCIMENTO, M. R.; SHIMIZU, E. S. C. L. Bijuterias, adornos e artesanatos: uso de sementes de espécies florestais como gemas orgânicas. Belém: Embrapa Amazônia Oriental, 2009.

LOBO, Samara; SARAIVA, Gisele Reis C. Artesãs criativas: processo de criação de biojoias. In: II Simpósio Internacional Interdisciplinar em Cultura e Sociedade - SIICS, 2., São Luís, 9 a 11 out. 2017. Anais do II Simpósio Internacional Interdisciplinar em Cultura e Sociedade. São Luís: Universidade Federal do Maranhão, 2017.

MANZINI, Ezio. VEZZOLI, Carlo. O desenvolvimento de produtos sustentáveis: requisitos ambientais dos produtos sustentáveis. São Paulo: Edusp, 2008.

MATOS, Eduardo; RODRIGUES, Marcelo Nascimento; VILELA, Denise. Dossiê Técnico: Tratamento Preventivo e Curativo de Sementes para Confecção de Artesanato. Brasília: UNB, 2007.

NORONHA, Raquel. Do centro ao meio: um novo lugar para o designer. In: Congresso Brasileiro de Pesquisa e Desenvolvimento em Design - P\&D, 10., São Luís, 10 a 13 out. 2012. Anais do 10응 Congresso Brasileiro de Pesquisa e Desenvolvimento em Design. São Luís: Universidade Federal do Maranhão, 2012.

PESKE, S.T.; ROSENTHAL, M.D.; ROTA, G.R.M. Sementes: Fundamentos científicos e tecnológicos. 3a edição. Pelotas: Editora rua Pelotas, 2012

SARAIVA, Gisele Reis C.; SANTOS, Tayomara Santos dos. Joias do Maracanã: tingimento natural de sementes. In: Colóquio Internacional de Design, 4. Belo Horizonte, 26 a 27 set. 2017. Anais do 49 Colóquio Internacional de Design. Belo Horizonte: Universidade do Estado de Minas Gerais, 2017.

SARAIVA, Gisele Reis C.; MORAES, Sâmela Patrícia Pereira. O design participativo no processo de geração da identidade visual das biojoias do Maracanã. Empreendedorismo, Gestão e Negócios, n.7, p. 314-334, mar 2018.

VALOIS, Afonso Celso Candeira. $O$ açaí: a nossa juçara. 2007. Disponível em: <http://www.acmma.com.br/acai.htm>. Acesso em 22 out. 2007. 